\title{
Azoospermia and reciprocal translocations: should whole-exome sequencing be recommended?
}

\author{
Farah Ghieh ${ }^{1,2}$, Anne-Laure Barbotin ${ }^{3}$, Julie Prasivoravong ${ }^{3}$, Sophie Ferlicot ${ }^{4}$, Béatrice Mandon-Pepin ${ }^{1,2}$, \\ Joanne Fortemps ${ }^{6}$, Henri-Jean Garchon ${ }^{7}$, Valérie Serazin ${ }^{1,2,5}$, Clara Leroy ${ }^{3}$, François Marcelli ${ }^{3}$ and \\ François Vialard ${ }^{1,2,5^{*}}$
}

\begin{abstract}
Background: Although chromosome rearrangements are responsible for spermatogenesis failure, their impact depends greatly on the chromosomes involved. At present, karyotyping and $Y$ chromosome microdeletion screening are the first-line genetic tests for patients with non-obstructive azoospermia. Although it is generally acknowledged that $\mathrm{X}$ or $\mathrm{Y}$ chromosome rearrangements lead to meiotic arrest and thus rule out any chance of sperm retrieval after a testicular biopsy, we currently lack markers for the likelihood of testicular sperm extraction (TESE) in patients with other chromosome rearrangements.

Results: We investigated the use of a single nucleotide polymorphism comparative genome hybridization array (SNP-CGH) and whole-exome sequencing (WES) for two patients with non-obstructive azoospermia and testicular meiotic arrest, a reciprocal translocation: $t(X ; 21)$ and $t(20 ; 22)$, and an unsuccessful TESE. No additional gene defects were identified for the $t(X ; 21)$ carrier - suggesting that $t(X ; 21)$ alone damages spermatogenesis. In contrast, the highly consanguineous t(20;22) carrier had two deleterious homozygous variants in the TMPRSS9 gene; these might have contributed to testicular meiotic arrest. Genetic defect was confirmed with Sanger sequencing and immunohistochemical assessments on testicular tissue sections.

Conclusions: Firstly, TMPRSS9 gene defects might impact spermatogenesis. Secondly, as a function of the chromosome breakpoints for azoospermic patients with chromosome rearrangements, provision of the best possible genetic counselling means that genetic testing should not be limited to karyotyping. Given the risks associated with TESE, it is essential to perform WES - especially for consanguineous patients.
\end{abstract}

Keywords: Meiotic arrest, Non-obstructive azoospermia, Translocation, Whole-exome sequencing, TMPRSS9

\footnotetext{
* Correspondence: francois.vialard@uvsq.fr

'Université Paris-Saclay, UVSQ, INRAE, BREED, F-78350 Jouy-en-Josas, France

¿École Nationale Vétérinaire d'Alfort, BREED, F-94700 Maisons-Alfort, France

Full list of author information is available at the end of the article
}

(C) The Author(s). 2021 Open Access This article is licensed under a Creative Commons Attribution 4.0 International License, which permits use, sharing, adaptation, distribution and reproduction in any medium or format, as long as you give appropriate credit to the original author(s) and the source, provide a link to the Creative Commons licence, and indicate if changes were made. The images or other third party material in this article are included in the article's Creative Commons licence, unless indicated otherwise in a credit line to the material. If material is not included in the article's Creative Commons licence and your intended use is not permitted by statutory regulation or exceeds the permitted use, you will need to obtain permission directly from the copyright holder. To view a copy of this licence, visit http://creativecommons.org/licenses/by/4.0/ The Creative Commons Public Domain Dedication waiver (http://creativecommons.org/publicdomain/zero/1.0/) applies to the data made available in this article, unless otherwise stated in a credit line to the data. 


\section{Résumé}

Contexte: Si les réarrangements chromosomiques sont connus pour être à l'origine d'une altération de la spermatogenèse, leur impact dépend fortement des chromosomes impliqués. À l'heure actuelle, la réalisation d'un caryotype et le dépistage des microdélétions du chromosome $Y$ sont les tests génétiques réalisés en première intention chez les patients atteints d'azoospermie non obstructive. S'il est généralement admis que les réarrangements impliquant les chromosomes $X$ ou $Y$ entrainent un arrêt méiotique et réduisent fortement les chances de retrouver des spermatozoïdes après une biopsie testiculaire, nous manquons de marqueurs permettant de définir une probabilité d'extraction de spermatozoïdes testiculaires chez les patients présentant d'autres réarrangements chromosomiques.

Résultats: Nous avons utilisé l'hybridation génomique comparative sur puces (SNP-CGH) et le séquençage entier de l'exome (SEE) pour deux patients présentant une azoospermie non obstructive avec arrêt méiotique, une translocation réciproque: $\mathrm{t}(\mathrm{X} ; 21)$ et $\mathrm{t}(20 ; 22)$, et sans spermatozoïde retrouvé après biopsie testiculaire Aucune autre anomalie génétique n'a été identifiée chez le patient porteur de la $t(X ; 21)$ - ce qui suggère que la translocation seule altére la spermatogenèse. En revanche, le patient porteur de la t(20;22), consanguin, présentait deux variants homozygotes délétères dans le gène TMPRSS9 qui pourraient contribuer à l'arrêt méiotique. Le variant génétique a été confirmé par séquençage Sanger et par immunohistochimie sur des coupes de tissu testiculaire.

Conclusions: Premièrement, nous faisons l'hypothèse d'un impact du défaut du gène TMPRSS9 sur la spermatogenèse. De plus, en fonction des points de cassures chromosomiques pour les patients azoospermes ayant une translocation réciproque, nous suggérons de ne pas limiter les analyses génétiques à la réalisation d'un caryotype afin d'affiner le conseil génétique. Compte tenu des risques associés à la TESE, il est essentiel de réaliser un SEE en amont et en particulier pour les patients consanguins.

Mots clés: Arrêt méiotique, azoospermie non obstructive, translocation, séquençage de l'exome, TMPRSS9.

\section{Introduction}

The World Health Organization defines azoospermia as the complete absence of spermatozoa in the semen. The prevalence of azoospermia in the male general population is around $1 \%[1,2]$. Azoospermia may have an excretory cause (obstruction of the seminal tract, leading to obstructive azoospermia) or a secretory cause (defective sperm production, leading to non-obstructive azoospermia $(\mathrm{NOA}))[1,2]$. In both cases, only recourse to an invasive surgical procedure, testicular sperm extraction (TESE) can potentially retrieve spermatozoa and thus enable the couple's subsequent participation in an in vitro fertilization programme [3]. In NOA, the TESE result depends on the three main testicular histological phenotypes: (i) early or late germ cell meiotic arrest (MA), (ii) Sertoli-cell-only syndrome (SCOS), and (iii) hypospermatogenesis with morphological mosaicism. One can also distinguish between pure phenotypes (in which all the seminiferous tubules have the same appearance) and mixed phenotypes (in which the tubules differ in appearance) [4]. TESE is generally negative in cases of pure MA and SCOS, and generally positive in cases of hypospermatogenesis.

Although NOA is likely to have a genetic cause, only a few genetic abnormalities have been specifically identified as recurrent causes of this condition; they include chromosomal aberrations (mainly 47,XXY-Klinefelter syndrome) [5] and Y chromosome microdeletions [6].
Recently, various researchers have used whole-genome analyses (especially array comparative genomic hybridization (CGH) and whole-exome sequencing (WES)) to identify genetic defects associated with spermatogenesis failure or NOA [7-9]. Only defects in Testis-expressed gene 11 (TEX11) gene are recurrently identified in NOA patients with MA. The list of gene mutations leading to NOA is growing and thus suggests that a large number of genes are involved in spermatogenesis [10]. Although genetic testing is currently used to help diagnose the aetiology of male infertility, it is not considered to be a prognostic tool for evaluating the likelihood of a positive TESE. In general, we need to find ways of preventing unnecessary TESE in NOA patients with genetic abnormalities. To date, AZFa and/or b microdeletions and a 46,XX karyotype are the only genetic abnormalities that counter-indicate TESE in NOA patients [11]. Conversely, it is now accepted that TESE will be successful in more than $40 \%$ of men with Klinefelter syndrome; this is due to testicular mosaicism and the presence of a few normal $46, \mathrm{XY}$ germ cells in the testis [12].

As with chromosomal rearrangements, the impact of translocations on spermatogenesis probably depends on the chromosomes involved. In cases of azoospermia, only translocations involving the $\mathrm{X}$ and $\mathrm{Y}$ chromosomes are thought to lead to spermatogenesis failure (due to impairment of the sex vesicle cycle) [13]. However, most 
andrologists agree that spermatogenesis failure cannot be explained by reciprocal or Robertsonian translocations or inversions alone (especially those involving autosomal chromosomes). The testicular environment might create a highly variable sperm count that ranges from normal to azoospermic. In such a context, a very low sperm count is likely to result from the combination of two genetic defects. With a view to better genetic counselling, the objective of the present study was to evaluate the potential utility of WES prior to TESE for azoospermic patients with reciprocal translocations. To this end, we performed WES for two patients with NOA (due to a reciprocal autosome-autosome translocation in one case and a gonosome-autosome translocation in the other).

\section{Materials and methods Patients \\ Case 1}

A 28-year-old man had failed to conceive after 2 years of unprotected intercourse. Two consecutive sperm analyses revealed azoospermia; this was confirmed after sperm centrifugation. The follicle-stimulating hormone (FSH) and inhibin B levels were $3.7 \mathrm{IU} / \mathrm{L}$ and $125 \mathrm{IU} / \mathrm{L}$, respectively. The semen biomarker levels (fructose, citrate, phosphatase acid, and alpha glucosidase) were respectively 102, 126, 3712 and $187 \mathrm{IU} / \mathrm{ml}$. A clinical examination found testicular volumes of 18 and $14 \mathrm{ml}$. Karyotyping and $\mathrm{Y}$ chromosome microdeletion screening revealed a reciprocal translocation: 46,Y,t(X;21)(q10; q10). Despite the karyotyping result and on the basis of the hormone and semen biomarker levels, the patient opted for TESE. No spermatozoa were retrieved, and complete MA at the spermatocyte I stage was diagnosed.

\section{Case 2}

A 39-year-old man had failed to conceive after 1.5 years of unprotected intercourse. Two consecutive sperm analyses revealed azoospermia; again, this was confirmed after sperm centrifugation. The FSH and inhibin B levels were $11.5 \mathrm{IU} / \mathrm{L}$ and $20 \mathrm{IU} / \mathrm{L}$, respectively. Semen biochemical assays were not performed for this patient. The testicular volume was low (between 6.8 and $7.2 \mathrm{ml}$ ). Karyotyping and $\mathrm{Y}$ chromosome microdeletion screening revealed a reciprocal translocation: 46,XY,t(20;22)(q11.2; p11.1). Despite the karyotyping result and after an unsuccessful resection for testicular varicocele, the patient opted for TESE. No spermatozoa were retrieved, and a complete MA at the spermatocyte I stage was diagnosed.

\section{Histological diagnosis}

A small piece of the testicular biopsy was fixed in Bouin's solution (MM France, Brignais, France) for $48 \mathrm{~h}$. Serial sections were prepared from paraffin blocks and stained with haematoxylin and eosin green FCF. All the sections were evaluated by the same expert histologist. Briefly, the mean seminiferous tubule diameter and the tubule wall thickness were measured on 100 seminiferous tubule cross-sections, using an eyepiece micrometre. The sections were classified according to the predominant histological pattern: Sertoli cell-only syndrome (SCOS, i.e. the absence of germ cells within the seminiferous tubules), maturation arrest (i.e. an absence of late-stage spermatogenesis, due to arrest at a particular stage), hypospermatogenesis (i.e. all stages of germ cell are present but in a low numbers), and normal or subnormal spermatogenesis. Furthermore, samples with maturation arrest were classified as "complete MA" when all the seminiferous tubules were affected. We specified the stage of the MA according to the most mature cell type observed during the histological assessment (e.g. MA at the spermatocyte I stage).

\section{Single nucleotide polymorphism comparative genome hybridization array analysis}

In order to detect copy number variations (CNVs) and losses of heterozygosity ( $\mathrm{LOH}$, also referred to as runs of homozygosity), we performed array-based single nucleotide polymorphism comparative genome hybridization (SNP-CGH; SurePrint G3 Human Genome CGH + SNP Microarray Kit, $2 \times 400 \mathrm{~K}$; Agilent Technologies, Santa Clara, CA 95,051, USA). The array was used according to the manufacturer's instructions, and commercially sourced male human genomic DNA (Agilent Technologies) was used as the control. Features were extracted from the scanned images using Feature Extraction software (version 4.0, Agilent Technologies) and analysed using the Aberration Detection Method 2 algorithm and CytoGenomics software (https://www.agilent.com/en/ genomics-software-downloads; Agilent Technologies). $\mathrm{LOH}$ also helped us to analyse the WES results. Furthermore, the total size of all $\mathrm{LOH}$ regions (tsLOH) provided us with an opportunity to calculate the inbreeding coefficient for each patient (defined as CsLOH regions/genome size: 3,138 Mb in hg19) according to the American College of Medical Genetics' standards [14], and to then compare it with the theoretical inbreeding coefficient [15].

\section{Whole-exome sequencing}

Exome sequencing was carried out by Eurofins Genomics (Ebresberg 85,560, Germany) using a HiSeq2500 sequencer (Illumina, San Diego, CA 92,122 USA) and DNA libraries made with Agilent's SureSelect Exome V6 + UTR Capture Library Kit, according to the manufacturer's instructions. Sequence reads were trimmed to remove read-through adaptors and low-quality sequences (using fastp [16]) and aligned against the 
GRCh38 build of the human genome (using the bwamem algorithm [17]). After the removal of PCR duplicates using Picard tools (https://broadinstitute.github.io/ picard/), the bases were recalibrated using the GATK (v4) tool Baserecalibrator (https://gatk.broadinstitute. org/hc/en-us), as recommended by the Broad Institute Genome Team [18]. Variants were then called with GATK haplotype Caller (https://gatk.broadinstitute.org/ hc/en-us), recalibrated with GATK VariantRecalibrator tool (https://gatk.broadinstitute.org/hc/en-us), and annotated with ANNOVAR (https://annovar. openbioinformatics.org/en/latest/) [19].

Only homozygous or compound heterozygous variants with an allele frequency $<1 \%$ in GnomAD and the 1000 Genomes project were included. We only retained variants causing insertions/deletions, missense, stop-loss, stop-gain or frameshift mutations, or changes to splice acceptor/donor sites. Synonymous and untranslated 3' or 5' regions variants were excluded. We selected missense variants with a high or moderate predicted effect on the encoded protein, as judged with the following prediction algorithms: REVEL (rare exome variant ensemble learner), SIFT (http://sift.jcvi.org/), Polyphen2 (http://genetics.bwh.harvard.edu/pph2/), and M-CAP (http://bejerano.stanford.edu/mcap/). Lastly, in order to identify variants potentially associated with MA, we only considered those in genes strongly or exclusively expressed in the testis or described as being essential for spermatogenesis and meiosis in the literature or in the Gene-Tissue Expression (https://gtexportal.org/home/), Human Protein Atlas (https://www.proteinatlas.org), PubMed or Ensembl databases.

\section{Sanger sequencing}

The variants observed in our analysis were confirmed with Sanger sequencing (carried out by Eurofins Genomics). Primers were designed using Primer 3 Plus software (http://primer3.ut.ee/), and 4 Peaks software (https:// nucleobytes.com/4peaks/) was used to read the chromatogram files generated by Eurofins. For each mutation, primers are reported in supplementary material and data (Supplemental Table 1).

\section{Immunohistochemical assessment}

DNMT3B (DNA methyltransferase 3B) and TMPRSS9 (transmembrane protease, serine 9) protein expression levels were assessed on testicular tissue sections from patient 2 and compared with those in a control subject with normal spermatogenesis and who had undergone a testicular biopsy for obstructive azoospermia. We used the Benchmark XT Ventana Roche immunohistochemistry (IHC) system and the XT UltraView Universal DAB Detection kit (Roche Life Science, Penzberg, Germany). To identify and localize the altered proteins in human testicular tissues, $4 \mu \mathrm{m}$ of paraffin-embedded testis sections from the patient and the control subject were prepared with a microtome. The sections were deposited on IHC slides (SuperFrost Plus type $25 \times 75 \times 1.0 \mathrm{~mm}$, Thermo Fisher Scientific, Waltham, MA, USA) and then dried at $56^{\circ} \mathrm{C}$ for $24 \mathrm{~h}$ to ensure good adhesion to the slide before staining. After the inhibition of endogenous peroxidases, the sections were incubated with the primary antibodies DNMT3B and TMPRSS9 (NBP1-85815 (1/500) and NBP2-30892 (1/100), NovusBio, Centennial, $\mathrm{CO}$, USA) $32 \mathrm{~min}$. After several rounds of washing, the antigen-antibody complex was visualized using the DAB detection system (Roche Life Science, Penzberg, Germany). Slides were counterstained with haematoxylin, dehydrated, and coverslipped for microscopy. Each experiment included negative controls not exposed to the primary antibody. Slides were examined under the microscope with a magnification of $x 40$.

\section{Results \\ Single nucleotide polymorphism comparative genome hybridization array analysis and WES}

We did not find any CNVs that could explain the patients' respective spermatogenesis defects. In particular, we did not find any deletions of the TEX11 gene -the most frequently altered gene in patients with MA, according to the literature data $[20,21]$. The inbreeding coefficient was low $(0.70 \%)$ for patient 1 and high $(5.38 \%)$ for patient 2 . These results prompted us to consider patient 2 as consanguineous and (especially for the latter patient) focus on regions of interest for WES.

For patient 1 (a 46,Y,t(X;21)(q10;q10) carrier), we did not find any SNVs that could have explained the MA. For patient 2 (a 46,XY,t(20;22)(q11.2;p11.1) carrier), and taking account of previously identified regions of interest with loss of heterozygosity, we identified a single homozygous single-nucleotide variant (SNV) in the DNMT3B gene (p.E115D, rs761700747) that had not previously been reported in the ExAC database (https://gnomad. broadinstitute.org). Given (i) the absence in the patient 2 of clinical signs of the immunodeficiency-centromeric instability-facial anomalies syndrome 1 (OMIM 242,860) associated with deleterious DNMT3B SNVs, and (ii) the high predicted variability associated with this SNV in the various databases (Table 1), we decided to screen the entire exome and to focus on genes that are strongly expressed in the testis. Three homozygous SNVs (p.T4A (rs8100709), p.R74W (rs142862960) and p.T1044I (rs72522121)) were identified in TMPRSS9 gene. Two of the $3 \mathrm{SNVs}$ were considered to be pathogenic and had a low frequency in general population (at 0.0011 and 0.0032 , respectively, according to gnomAD). The data are summarized in Table 1 . The variants observed in our analysis were confirmed with Sanger sequencing. 
Table 1 Homozygous SNPs identified for patient 2, using WES

\begin{tabular}{lllcllll}
\hline Gene & Mutation & Type & Frequency (gnomAD) & M-CAP & Revel & SIFT & Polyphen2 \\
\hline TMPRSS9 & T4A & homozygous & 0.0138 & unknown & benign & benign & benign \\
& R74W & homozygous & 0.0011 & unknown & benign & deleterious & deleterious \\
& T1044l & homozygous & 0.0032 & unknown & deleterious & deleterious & deleterious \\
DNMT3B & E115D & homozygous & $<0.0001$ & deleterious & benign & benign & probably deleterious \\
\hline
\end{tabular}

\section{Immunohistochemical assessment}

In normal spermatogenesis, the TMPRSS9 protein is located in the nuclei of the spermatogonia (control subject: Fig. 1A), and the DNMT3B protein is located in the nuclei of spermatocytes (control subject: Fig. 1C). For patient 2, the seminiferous tubules (containing germs cells arrested at the spermatocyte stage) were not stained (Fig. 1B and D). In contrast, strong DNMT3B staining was detected in the cytoplasm of Leydig cells for the patient 2 but not for the control. These results suggested that the SNVs identified in patient 2 were linked to his testicular phenotype.

\section{Discussion}

\section{The SNVs' impact on spermatogenesis}

We identified three rare variants for patient 2 and then developed a hypothesis for the possible link between consanguinity, maturation arrest during spermatogenesis, and gene defects. The three TMPRSS9 mutations all occurred in the isoform ENST00000332578.7, which is strongly expressed in testis. Both TMPRSS9 and DNMT3B proteins are strongly expressed in testes, according to the Gene-Tissue Expression database and the Human Protein Atlas. Although TMPRSS9 mRNA expression has also been reported in the liver and spleen, there are no data on protein levels in these organs. High levels of DNMT3B mRNA expression are also observed in testes. The DNMT3B protein appears to be present in many tissues, with the highest levels in testis and placenta. An IHC assessment of a testicular biopsy from a control subject with a positive TESE and complete spermatogenesis revealed strong TMPRSS9 protein staining in the nuclei of spermatogonia $\mathrm{A}$ and $\mathrm{B}$ and strong DNMT3B protein staining in spermatocytes. These results were in line with the expression data recorded in the Human Protein Atlas and indicated that TMPRSS9 is expressed earlier than DNMT3B in the seminiferous tubules during normal spermatogenesis. If a defect in the TMPRSS9 gene does indeed cause MA, it would presumably occur at the spermatogonia stage (i.e. before DNMT3B expression). More generally, the absence of TMPRSS9 is associated with the absence of all the proteins expressed downstream (e.g. DNMT3B); this might explain the absence of protein expression in patient 2's testicular biopsy. Furthermore, many pathogenic allelic variants in DNMT3B have been identified [22, 23], all of which were associated with the immunodeficiency-

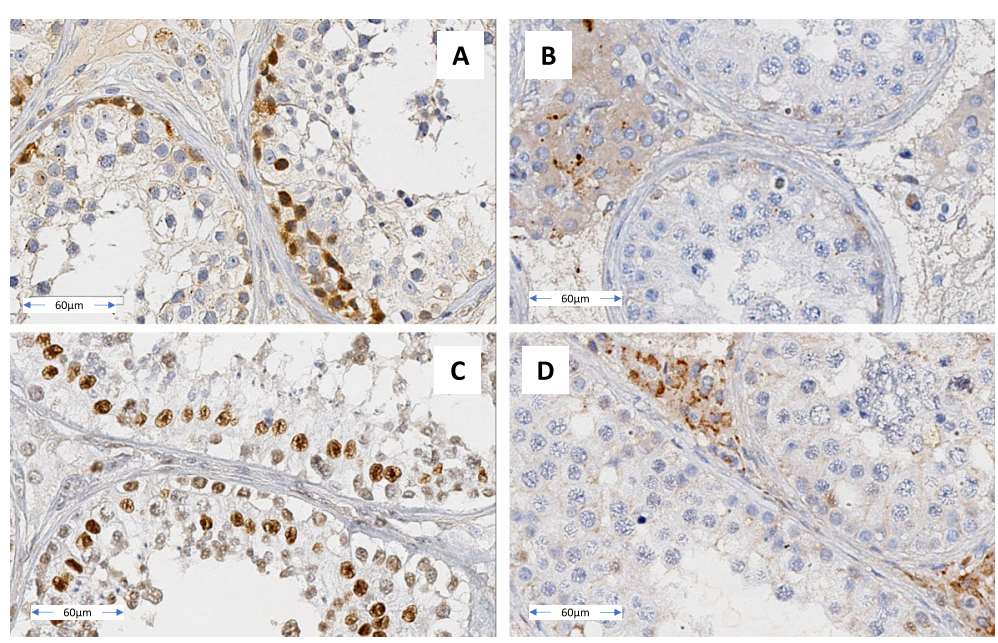

Fig. 1 Immunohistochemical assessment of seminiferous tubule expression of TMPRSS9 (A: control; B: patient 2) and DNMT3B (C: control; D: patient 2) in the testes. $\mathbf{A}$ and $\mathbf{C}$ : normal spermatogenesis, showing normal expression of TMPRSS9 and DNMT3B. B and D: spermatogenesis arrested at the spermatocyte stage, with no expression of TMPRSS9 or DNMT3B. Staining: the antigen-antibody complex was visualized with the DAB detection system, and slides were counterstained with haematoxylin 
centromeric instability-facial anomalies syndrome 1 (ICF1) (OMIM 242,860). The variants spanned the entire sequence, and there were no hotspots. Taking into account the great variability in the SNV's impact predicted by the various databases and in the absence of clinical manifestations of ICF1 syndrome, we conclude that the DNMT3B SNV did not have an effect on spermatogenesis. We therefore hypothesize that TMPRSS9 gene defects (caused here by 2 rare pathogenic SNVs) may impair meiosis and lead to a spermatogenic defect. Further experiments will be necessary to refine our results for TMPRSS9 and to characterize its putative functional role during spermatogenesis; this role has never been studied, even though the gene is known to be mainly or exclusively expressed in the testis. To date, TMPRSS9 variants have been only reported in a single patient with autism spectrum disorders [24], who was a compound heterozygote for 2 frameshift mutations. Only one homozygous Tmprss 9 knockout mice has been reported in literature, with an exon 2 deletion. [25]. If mice were fertile, a residual Tmprss 9 mRNA expression could be observed; however, no definitive conclusions could be drawn with regard to fertility. In order to understand the impact of TMPRSS9 on spermatogenesis, new null mouse models (i.e. models lacking mRNA expression) should be designed.

\section{The impact of reciprocal translocation on spermatogenesis}

Reciprocal translocations between two autosomes are the most frequent structural chromosomal abnormalities in humans. The prevalence of chromosomal abnormalities is 6.5 times higher in infertile male adults than in newborns [26]. Chromosome screening studies have established the relationship between the sperm count on one hand and the frequencies and types of chromosomal abnormalities on the other. It appears that reciprocal translocations involving only autosomes are more frequent in oligozoospermia, and that those involving gonosomes are associated with severe male infertility and azoospermia [27]. Gonosome-autosome translocations are rare and are divided into three groups, depending on the gonosome involved: $\mathrm{Y}$-autosome translocations (i.e. $\mathrm{t}(\mathrm{Y} ; \mathrm{A})), \mathrm{X}$-autosome translocations (i.e. $\mathrm{t}(\mathrm{X} ; \mathrm{A})$ ), and $\mathrm{X}-\mathrm{Y}$ translocations. Spermatogenetic arrest at the pachytene stage is mainly due to disruption of sex vesicle formation by the quadrivalent observed in all translocation segregations [28]. However, the majority of these patients have severe oligozoospermia and are infertile. For $\mathrm{t}(\mathrm{Y} ; \mathrm{A})$, it has been hypothesized that a smaller translocation segment is associated with more frequent bivalent formation and a higher sperm count [29]. This hypothesis was based on the sperm segregation pattern. In the few patients who showed spermatogenesis, the great majority of spermatozoa were derived from alternate and adjacent segregation. For $\mathrm{t}(\mathrm{X}, \mathrm{A})$, the interpretation was more complicated (as in our present case): various breakpoints were described, and the sperm segregation pattern was high variable [30]. The size of the segment involved in the translocation does not appear to be related to the TESE result. Although autosome (chromosome 1) breakpoints and X chromosome breakpoints are unusually frequent in male infertility [31], the breakpoint profile does not have prognostic value for TESE. Nevertheless, it has been suggested that the presence of an acrocentric chromosome is associated with a poor prognosis [32]. It has also been reported that a poor TESE prognosis is associated with the $\mathrm{XY}$ body in rearrangements involving an acrocentric chromosome [33] and an abnormally high frequency of breakpoints on an acrocentric p-arm in infertile patients [31].

\section{The "two genetic defects" hypothesis}

Taken as a whole, these data suggest that the $t(X ; A)$ alone could explain MA in patient 1 (with idiopathic azoospermia and normal testicular volume). This hypothesis was strengthened by the absence of a pathological variant in the WES analysis. In contrast, the reciprocal translocation alone could not explain the MA for patient 2. However, the combination of the reciprocal translocation with the 3 rare variants of TMPRSS9 (2 of which were considered to be deleterious in predictive databases) could probably explained the spermatogenesis phenotype. These observations strengthen the "two genetic defects" hypothesis for spermatogenesis failure, as has been seen for several other pathologies [34].

In view of the present two cases, the possible impact of a reciprocal translocation on spermatogenesis should be discussed more widely during genetic counselling. Should TESE be suggested, therefore, in patients with a reciprocal translocation? In such a case, one must take account of additional genetic abnormalities. In order to evaluate the probability of successful TESE, we suggest that WES could be performed after considering the chromosome involved, the chromosome breakpoints, and the patient's family medical history. As described above, $t(X ; A)$ was probably the main cause of MA in patient 1 . Considering this reciprocal translocation and the high probability of inheriting unbalanced chromosomes (due to translocation malsegregation), the probability of sperm retrieval with TESE is probably very low; this point should be discussed with the patient prior to surgery. We now require more data on when TESE should be ruled out completely. In contrast, the reciprocal translocation alone could not explain patient 2's testicular phenotype. If the inbreeding coefficient is high, WES should be considered - even though the scarcity of 
literature data on the TMPRSS9 gene prevents us drawing clear conclusions about TESE.

\section{Limitations of the WES approach}

WES provides an opportunity to map defects in genes involved in early or late germ cell meiotic arrest. However, a number of complicating factors must be borne in mind: the need for informed consent from the patient, the requirement for pre- and post-test genetic counselling, the complexity of data interpretation, and the cost. In order to limit the complexity and reduce the costs, we decided to focus solely on genes primarily or exclusively expressed in the testis; this would hopefully avoid the fortuitous discovery of gene defects associated with other pathologies (such as cancer) to limit patient feedback and the implications for the patient's family. Even though WES data are still time-consuming to interpret, the development of novel software tools should soon facilitate the identification and interpretation of all genetic variants. Although the present study might constitute the first step in a larger study, we would nevertheless consider implementing whole-genome sequencing as a replacement for WES and karyotyping.

\section{Conclusion}

Prior to TESE, genetic counselling is important for patients with a reciprocal translocation: discussion of the high probability of inheriting unbalanced chromosomes, and evaluation of the family history. However, our case reports also suggest that WES should be recommended for consanguineous patients, in order to better define the likelihood of sperm retrieval and with a focus on genes primarily or exclusively expressed in the testis. Furthermore, we suggest that deleterious TMPRSS9 variants impact spermatogenesis - although further data are required.

\section{Abbreviations \\ AZF: Azoospermia factor; CGH: Comparative genome hybridization; CNV: Copy number variation; TsLOH: Total size of all LOH regions; DNMT3B: DNA methyltransferase 3B; FSH: Follicle-stimulating hormone: LOH: Loss of heterozygosity; MA: Meiotic arrest; Mb: Megabase; NOA: Non- obstructive azoospermia; SCOS: Sertoli-cell-only syndrome; SNP: Single nucleotide polymorphism; SNV: Single nucleotide variant; TEX11: Testis- expressed gene 11; TESE: Testicular sperm extraction; TMPR \\ SS9: Transmembrane protease, serine 9; WES: Whole-exome sequencing}

\section{Supplementary Information}

The online version contains supplementary material available at https://doi. org/10.1186/s12610-021-00145-5.

Additional file 1 : Supplemental Table 1. Primers used for Sanger sequencing in this study.

\section{Authors' contributivon's}

FG: performed immunochemistry, Sanger confirmation, variant prioritization and wrote the paper. ALB: performed histological and TESE analysis. JP, CL: performed the clinical examination and TESE surgery. SF: supervised the immunochemistry analysis, revised the paper. BMP: revised the paper and supervised the study. JF: performed the immunochemistry analysis. HJG: supervised variant prioritization, revised the paper. VS: supervised Sanger analysis, revised the paper. FM: performed the clinical examination and TESE surgery, revised the paper. FV: designed the study, wrote the paper. The author(s) read and approved the final manuscript.

\section{Funding}

Fondation maladies rares: https://fondation-maladiesrares.org, IRSF: http:// www.irsf.fr.

\section{Availability of data and materials}

All supporting data are available.

\section{Declarations}

Ethics approval and consent to participate

The present study was approved by an independent ethics committee (CPP Ile de France-Ouest, Paris, France; reference: 01-132). Both patients gave their written informed consent to publication of their personal health data.

\section{Consent for publication}

All authors gave their consent for publication.

\section{Competing interests}

None.

\section{Author details}

'Université Paris-Saclay, UVSQ, INRAE, BREED, F-78350 Jouy-en-Josas, France. 2École Nationale Vétérinaire d'Alfort, BREED, F-94700 Maisons-Alfort, France. ${ }^{3}$ Institut de Biologie de la Reproduction-Spermiologie-CECOS, Hôpital Jeanne de Flandre, Centre Hospitalier et Universitaire, F-59000 Lille, France. ${ }^{4}$ Service d'Anatomie Pathologique, AP-HP, Université Paris-Saclay, Hôpital de Bicêtre, F-94270 Le Kremlin-Bicêtre, France. ${ }^{5}$ Département de Génétique, Laboratoire de Biologie Médicale, CHI de Poissy/Saint-Germain- en-Laye, F-78300 Poissy, France. ${ }^{6}$ Service d'Anatomie Pathologique, CHI de Poissy/

Saint-Germain-en-Laye, F-78100 Saint- Germain-en-Laye, France. ${ }^{7}$ UMR1179, UVSQ, F-78180 Montigny le Bretonneux, France.

Received: 21 April 2021 Accepted: 7 September 2021

Published online: 11 November 2021

\section{References}

1. Foresta C, Ferlin A, Bettella A, Rossato M, Varotto A. Diagnostic and clinical features in azoospermia. Clin Endocrinol (Oxf). 1995;43:537-43.

2. Willott GM. Frequency of azoospermia. Forensic Sci Int. 1982;20:9-10.

3. Donoso P, Tournaye H, Devroey P. Which is the best sperm retrieval technique for non-obstructive azoospermia? A systematic review. Hum Reprod Update. 2007;13:539-49.

4. Robin G, Boitrelle F, Leroy X, Peers M-C, Marcelli F, Rigot J-M, et al. [Assessment of azoospermia and histological evaluation of spermatogenesis]. Ann Pathol. 2010;30:182-95.

5. De Braekeleer M, Dao TN. Cytogenetic studies in male infertility: a review. Hum Reprod. 1991;6:245-50.

6. Vogt P, Chandley AC, Hargreave TB, Keil R, Ma K, Sharkey A. Microdeletions in interval 6 of the $Y$ chromosome of males with idiopathic sterility point to disruption of AZF, a human spermatogenesis gene. Hum Genet. 1992;89: 491-6.

7. Cannarella R, Condorelli RA, Paolacci S, Barbagallo F, Guerri G, Bertelli M, et al. Next-generation sequencing: toward an increase in the diagnostic yield in patients with apparently idiopathic spermatogenic failure. Asian J Androl. 2020;23(1):24-9.

8. Krausz C, Riera-Escamilla A, Moreno-Mendoza D, Holleman K, Cioppi F, Algaba F, et al. Genetic dissection of spermatogenic arrest through exome analysis: clinical implications for the management of azoospermic men. Genet Med. 2020;22:1956-66. 
9. Ben Khelifa M, Ghieh F, Boudjenah R, Hue C, Fauvert D, Dard R, et al. A MEl1 homozygous missense mutation associated with meiotic arrest in a consanguineous family. Hum Reprod. 2018;33:1034-7.

10. Matzuk MM, Lamb DJ. The biology of infertility: research advances and clinical challenges. Nat Med. 2008;14:1197-213.

11. Punjani N, Kang C, Schlegel PN. Clinical implications of $Y$ chromosome microdeletions among infertile men. Best Pract Res Clin Endocrinol Metab. 2020 Dec;34(6):101471.

12. Vialard F, Bailly M, Bouazzi H, Albert M, Pont JC, Mendes V, et al. The high frequency of sperm aneuploidy in klinefelter patients and in nonobstructive azoospermia is due to meiotic errors in euploid spermatocytes. J Androl. 2012;33:1352-9.

13. Vialard F, Molina-Gomes D, Roume J, Podbiol A, Hirel C, Bailly M, et al. Case report: meiotic segregation in spermatozoa of a $46, X, t(Y ; 10)(q 11.2 ; p 15.2)$ fertile translocation carrier. Reprod Biomed Online. 2009;18:549-54.

14. Wierenga KJ, Jiang Z, Yang AC, Mulvihill JJ, Tsinoremas NF. A clinical evaluation tool for SNP arrays, especially for autosomal recessive conditions in offspring of consanguineous parents. Genet Med. 2013;15:354-60.

15. Sund $K L$, Zimmerman SL, Thomas C, Mitchell AL, Prada CE, Grote L, et al. Regions of homozygosity identified by SNP microarray analysis aid in the diagnosis of autosomal recessive disease and incidentally detect parental blood relationships. Genet Med. 2013 Jan;15(1):70-8.

16. Chen S, Zhou Y, Chen Y, Gu J. fastp: an ultra-fast all-in-one FASTQ preprocessor. Bioinformatics. 2018;34:1884-90.

17. Li H. Aligning sequence reads, clone sequences and assembly contigs with BWA-MEM. arXiv:13033997 [q-bio]. 2013 [cited 2021 Feb 26]; Available from: http://arxiv.org/abs/1303.3997 "Preprint manuscript (2013)\&\#8221.

18. DePristo MA, Banks E, Poplin R, Garimella KV, Maguire JR, Hartl C, et al. A framework for variation discovery and genotyping using next-generation DNA sequencing data. Nat Genet. 2011:43:491-8.

19. Wang K, Li M, Hakonarson H. ANNOVAR: functional annotation of genetic variants from high-throughput sequencing data. Nucleic Acids Res. 2010;38: e164.

20. Yatsenko AN, Georgiadis AP, Röpke A, Berman AJ, Jaffe T, Olszewska M, et al. X-linked TEX11 mutations, meiotic arrest, and azoospermia in infertile men. N Engl J Med. 2015;372:2097-107.

21. Sha $Y$, Zheng $L$, Ji Z, Mei $L$, Ding $L$, Lin $S$, et al. A novel TEX11 mutation induces azoospermia: a case report of infertile brothers and literature review. BMC Med Genet. 2018;19:63.

22. Jiang $Y L$, Rigolet $M$, Bourc'his D, Nigon F, Bokesoy I, Fryns JP, et al. DNMT3B mutations and DNA methylation defect define two types of ICF syndrome. Hum Mutat. 2005;25:56-63.

23. Xie Z-H, Huang Y-N, Chen Z-X, Riggs AD, Ding J-P, Gowher $H$, et al. Mutations in DNA methyltransferase DNMT3B in ICF syndrome affect its regulation by DNMT3L. Hum Mol Genet. 2006;15(9):1375-85.

24. Aragam N, Wang K-S, Anderson JL, Liu X. TMPRSS9 and GRIN2B are associated with neuroticism: a genome-wide association study in a European sample. J Mol Neurosci. 2013;50:250-6.

25. Chen C-A, Pal R, Yin J, Tao H, Amawi A, Sabo A, et al. Combination of whole exome sequencing and animal modeling identifies TMPRSS9 as a candidate gene for autism spectrum disorder. Hum Mol Genet. 2020;29:459-70.

26. Bourrouillou G, Mansat A, Calvas P, Pontonnier F, Colombies P. [Chromosome anomalies and male infertility. A study of 1,444 subjects]. Bull Assoc Anat (Nancy). 1987;71:29-31.

27. Van Assche $E$, Bonduelle $M$, Tournaye $H$, Joris $H$, Verheyen $G$, Devroey $P$, et al. Cytogenetics of infertile men. Hum Reprod. 1996;11(Suppl 4):1-24 discussion 25-26.

28. Gabriel-Robez O, Ratomponirina C, Dutrillaux B, Carré-Pigeon F, Rumpler Y. Meiotic association between the $X Y$ chromosomes and the autosomal quadrivalent of a reciprocal translocation in two infertile men, 46,XY,t(19;22) and 46,XY,t(17;21). Cytogenet Cell Genet. 1986;43:154-60.

29. Vialard F, Molina-Gomes D, Roume J, Podbiol A, Hirel C, Bailly M, et al. Case report: Meiotic segregation in spermatozoa of a $46, X, t(Y ; 10)(q 11.2 ; p 15.2)$ fertile translocation carrier. Reprod Biomed Online. 2009;18:549-54.

30. Perrin A, Vialard F, Douet-Guilbert N, Gomes DM, Guthauser B, De Braekeleer $\mathrm{M}$, et al. Meiotic segregation of $\mathrm{X}$-autosome translocation in two carriers and implications for assisted reproduction. Reprod Biomed Online. 2009;18: 850-5.

31. Bache I, Assche EV, Cingoz S, Bugge M, Tümer Z, Hjorth M, et al. An excess of chromosome 1 breakpoints in male infertility. Eur J Hum Genet. 2004;12: 993-1000.
32. Vialard F, Nouchy M, Malan V, Taillemite J-L, Selva J, Portnoï M-F. Whole-arm translocations between chromosome 1 and acrocentric $\mathrm{G}$ chromosomes are associated with a poor prognosis for spermatogenesis: two new cases and review of the literature. Fertil Steril. 2006:86:1001.e1-5.

33. Luciani JM, Guichaoua MR, Delafontaine D, North MO, Gabriel-Robez O, Rumpler Y. Pachytene analysis in a 17;21 reciprocal translocation carrier: role of the acrocentric chromosomes in male sterility. Hum Genet. 1987;77:246-50.

34. Pavone P, Pappalardo XG, Incorpora G, Falsaperla R, Marino SD, Corsello G, et al. Long-term follow-up and novel genotype-phenotype analysis of monozygotic twins with ATP1A3 mutation in Alternating Hemiplegia of Childhood-2. Eur J Med Genet. 2020:63:103957.

\section{Publisher's Note}

Springer Nature remains neutral with regard to jurisdictional claims in published maps and institutional affiliations.
Ready to submit your research? Choose BMC and benefit from:

- fast, convenient online submission

- thorough peer review by experienced researchers in your field

- rapid publication on acceptance

- support for research data, including large and complex data types

- gold Open Access which fosters wider collaboration and increased citations

- maximum visibility for your research: over $100 \mathrm{M}$ website views per year

At BMC, research is always in progress.

Learn more biomedcentral.com/submissions 